\title{
$\alpha 7$ Nicotinic acetylcholine receptor-mediated anti-inflammatory effect in a chronic migraine rat model via the attenuation of glial cell activation
}

This article was published in the following Dove Press journal: Journal of Pain Research

\author{
Qing Liu' \\ Chaoyang Liu' \\ Li Jiang' \\ Maolin $\mathrm{Li}^{\prime}$ \\ Ting Long' \\ Wei $\mathrm{He}^{1}$ \\ Guangcheng Qin ${ }^{2}$ \\ Lixue Chen ${ }^{2}$ \\ Jiying Zhou'
}

'Department of Neurology, The First Affiliated Hospital, Chongqing Medical University, Chongqing, China; ${ }^{2}$ Laboratory Research Center, The First Affiliated Hospital, Chongqing Medical University, Chongqing, China
Correspondence: Jiying Zhou Department of Neurology, The First Affiliated Hospital, Chongqing Medical University, Ist You Yi Road, Yu Zhong District, Chongqing 400016, China Email zheadache@I63.com
Background: Evidence suggests that the activation of $\alpha 7$ nicotinic acetylcholine receptor $(\alpha 7 \mathrm{nAChR})$ can greatly decrease the neuroinflammation response. Neuroinflammation plays a pivotal role in the pathogenesis of chronic migraine (CM). Clinical observations also show that nicotine gum induces analgesic effects in migraine patients. However, whether $\alpha 7 \mathrm{nAChR}$ is involved in $\mathrm{CM}$ is unclear.

Objective: To investigate the role of $\alpha 7 \mathrm{nAChR}$ in $\mathrm{CM}$ and provide a new therapeutic target for CM.

Materials and methods: Thirty-six male Sprague-Dawley rats were distributed randomly into control, CM, PNU-282987, and $\alpha$-bungarotoxin groups ( $\mathrm{n}=9$ rats in each group). The CM model was established by the recurrent daily administration of inflammatory soup on the dura over the course of 1 week. The hind paw threshold and facial allodynia were assessed by the von Frey test. The expression levels of $\alpha 7 \mathrm{nAChR}$, tumor necrosis factor-alpha, and interleukin-1 beta were analyzed by Western blot and real-time fluorescence quantitative polymerase chain reaction. The location of $\alpha 7 \mathrm{nAChR}$ in the hippocampus was quantified by immunofluorescence, as well as the microglial and astrocyte alterations. Changes in the calcitonin gene-related peptide and the phosphorylated JNK protein among different groups were measured by Western blot.

Results: We found that the expression of $\alpha 7 \mathrm{nAChR}$ was reduced after repeated inflammatory soup administration. The increased expression of tumor necrosis factor-alpha, interleukin-1 beta, and calcitonin gene-related peptide in CM group were significantly decreased by PNU282987 and aggravated by $\alpha$-bungarotoxin. Moreover, PNU-282987 decreased the numbers of astrocytes and microglia compared with the numbers in the CM group in both hippocampal CA1 and CA 3 regions. In contrast, $\alpha$-bungarotoxin activated the astrocytes and microglia, but the differences with respect to the CM group were not significant. Activated c-Jun N-terminal kinase signaling was observed in CM rats and was also blocked by PNU-282987.

Conclusion: The activation of $\alpha 7 \mathrm{nAChR}$ increased the mechanical threshold and alleviated pain in the $\mathrm{CM}$ rat model. $\alpha 7 \mathrm{nAChR}$ activation also decreased the upregulation of astrocytes and microglia through the $\mathrm{p}$-c-Jun N-terminal kinase-mitogen-activated protein kinase signaling pathway.

Keywords: chronic migraine, $\alpha 7 \mathrm{nAChR}$, analgesia, glial activation, neuroinflammation, nociception

\section{Introduction}

Patients with chronic migraine (CM) exhibit functional disability, and CM is refractory to treatment. ${ }^{1}$ However, the pathophysiological mechanisms of CM are complex and have not yet been fully established. Numerous studies suggest that pro-inflammatory 
cytokine levels are increased in $\mathrm{CM}^{2-4}$ and recent evidence has also indicated that the transcription of inflammatory genes is upregulated in CM patients. ${ }^{5}$ This finding implies that inflammation, especially neuroinflammation, is part of the core pathogenesis of $\mathrm{CM}^{6}{ }^{6}$ In vivo and in vitro experiments have demonstrated that the activation of astrocyte and microglia accelerates the expression of pro-inflammatory cytokines $^{7,8}$ and have also shown that microglial activation contributes to acute pain and that astrocyte activation, in turn, maintains allodynia. ${ }^{9}$ Furthermore, both microglia and astrocytes were recently showed to participate in cortical spreading depression-related diseases, such as migraine. ${ }^{10,11}$ Therefore, we assumed the cause of the inflammatory cytokine expression in $\mathrm{CM}$ to be the activation of glial cells.

Clinical research has shown that nicotine gum has an analgesic effect. ${ }^{12}$ Cholinergic modulation attenuates systemic inflammatory responses. ${ }^{13,14}$ A prophylactic approach to migraine involves the activation of the cholinergic antiinflammatory pathway (CAP).$^{15} \alpha 7$ nicotinic acetylcholine receptor $(\alpha 7 \mathrm{nAChR})$ is one of the ligand-gated ion channels in the CAP. After combining with signaling molecules, these ionic channel-linked receptors could significantly modulate the membrane permeability and neurotransmitter expression. A series of studies have proved that $\alpha 7 \mathrm{nAChRs}$ participate in neuroprotection. ${ }^{16-18} \alpha 7 \mathrm{nAChR}$ activation exhibits significant anti-inflammatory effects in neuroinflammation, ${ }^{19,20}$ and $\alpha 7 \mathrm{nAChR}$ agonists have also been shown to attenuate hyperalgesic effects in chronic neuropathic pain..$^{21,22}$ In a previous rodent study, deficient antinociceptive effects were observed in $\alpha 7 \mathrm{nAchR}$ knockout mice compared with their littermate controls when treated with choline. ${ }^{23}$ The activation of astrocytes and microglia is known to play a pivotal role in the progression of pain. ${ }^{10,24}$ Furthermore, numerous studies have demonstrated that $\alpha 7 \mathrm{nAChR}$ activation significantly suppresses glial activation. ${ }^{25-27} \mathrm{An}$ in vitro trial showed that the activation of $\alpha 7 \mathrm{nAChR}$ promoted the conversion of M1 microglia to the M2 phenotype ${ }^{28}$ These results suggest that activated $\alpha 7 \mathrm{nAChR}$ may contribute to the inhibition of glial activation and further to the regulation of $\mathrm{CM}$ conditions. However, to date, this assumption has not been verified in a CM rat model.

Hippocampus had long been associated with cognitive, while more and more studies showed that the hippocampus was involved in pain-related attention ${ }^{29}$ and pain processing, such as migraine. ${ }^{30} \mathrm{Clinical}$ studies suggested the hippocampal volume was initially changed in low frequency migraines, this plasticity maladaptive decreased in the long term in $\mathrm{CM}^{31-33}$ The hippocampal activation was also linked to headache frequency. ${ }^{30} \alpha 7 \mathrm{nAChRs}$ were predominant in hippocampal
CA1, CA3 layers and dentate gyrus layer, both in humans ${ }^{34}$ and rodents. ${ }^{35,36} \mathrm{PNU}-282987$ was an agonist of $\alpha 7 \mathrm{nAChR}$ and its effect could be completely blocked by $\alpha$-bungarotoxin. ${ }^{37,38}$ $\left[{ }^{125} \mathrm{I}\right] \alpha$-bungarotoxin was actually with a close distribution to $\alpha 7 \mathrm{nAChR}$ in human hippocampus. ${ }^{34}$ Therefore, we selected the hippocampus to study $\alpha 7 \mathrm{nAChR}$ in $\mathrm{CM}$.

Calcitonin gene-related peptide (CGRP) is a potent vasodilator and pain-signaling neuropeptide and is strongly implicated in the pathophysiology of migraine. ${ }^{39} \mathrm{CGRP}$ is a trigger of migraine attacks. ${ }^{40}$ CGRP antibodies had shown promising effects in both episodic migraine and CM..$^{41,42}$ Pro-inflammatory cytokine, especially tumor necrosis factoralpha (TNF- $\alpha$ ), might increase the production of CGRP and exacerbate the pathophysiology of migraine. ${ }^{43}$ Cytokines were known to activate different signaling pathways, such as the mitogen-activated protein kinase (MAPK) pathways. MAPK cascade also increased CGRP expression during migraine. ${ }^{44} \mathrm{~A}$ vivo experiment suggested that the c-Jun $\mathrm{N}$-terminal kinase (JNK) signaling pathway was obligate to the manifestation of inflammatory soup (IS)-induced nociceptive behavior. ${ }^{45}$ Consequently, we speculated that $\alpha 7 \mathrm{nAChR}$ might work through the phosphorylated (p)-JNK-MAPK signaling pathway.

We aimed to explore whether $\alpha 7 \mathrm{nAChR}$ activation produces anti-allodynic and anti-inflammatory effects in a rat model of CM. PNU-282987 and $\alpha$-Bungarotoxin were used to further explore its role in the neuroimmune activity of the central nervous system (CNS).

\section{Materials and methods}

\section{Animals}

Healthy adult male Sprague-Dawley rats weighing 260 $320 \mathrm{~g}$ were housed 1 per cage at a temperature of $23^{\circ} \mathrm{C} \pm 1^{\circ} \mathrm{C}$ and a 12-hour light-dark cycle with food and water available ad libitum. All treatment protocols were performed according to the guidelines of the Animal Care and Use Committee at Chongqing Medical University in China and were consistent with the National Institutes of Health Guide for the Care and Use of Laboratory Animals. The Animal Care and Use Committee at Chongqing Medical University approved this research. Since the animals were to be in pain, the number of rats studied was restricted to the minimum necessary. The final numbers are detailed in each figure.

\section{CM model}

Based on previous research, $8.0 \mathrm{~g}$ (facial) and $15.0 \mathrm{~g}$ (hind paw) were used as tactile stimulus thresholds. ${ }^{46}$ Repeated meningeal administration of IS was used to study nociception in $\mathrm{CM}^{.47,48}$ All animals were placed in a stereotaxic apparatus 
(ST-51603; Stoelting Co., Chicago, IL, USA) after general anesthesia. The rats were sterilized with chlorhexidine $(10 \%$ solution) and then fitted with a cranial chamber. A craniotomy $1 \mathrm{~mm}$ in diameter $(+1.5 \mathrm{~mm}$ from the bregma and $+1 \mathrm{~mm}$ lateral) was performed above the dura, with care not to damage the dura. A stainless steel cannula with a removable cap (cata$\log$ no. 62101/62001; RWD, Shenzhen, China) was affixed to the bone with dental cement. After suturing, the rats were returned to a temperature-controlled electric heating blanket until recovery was complete and they regained consciousness. After 1 week of recovery, the meningeal administration of IS or PBS was successively performed for 7 days.

\section{Groups and treatment}

Rats were randomly divided into 4 groups: the control, CM, PUN-282987, and $\alpha$-bungarotoxin groups. In the control group, $2 \mu \mathrm{L}$ of PBS (0.1 M, pH 7.4) was slowly infused through the cannula. In the other 3 groups, $2 \mu \mathrm{L}$ of IS was infused. The IS contained $1 \mathrm{mM}$ histamine, serotonin, and bradykinin and $0.1 \mathrm{mM}$ prostaglandin E2 (all from Sigma, St. Louis, MO, USA). After 7 days of exposure by infusion, the vehicle (PBS, 0.1 M, pH 7.4) was administered by intracerebroventricular (I.C.V) injection to the control and CM groups, and PNU-282987 (2.5 $\mu \mathrm{mol} / \mathrm{animal}, \mathrm{P} 6499-10 \mathrm{MG}$; Sigma) and $\alpha$-bungarotoxin (1.0 $\mu \mathrm{g} / \mathrm{animal}, \mathrm{ab} 120542$; Abcam, Cambridge, MA, USA) were administered to the PNU-282987 and $\alpha$-bungarotoxin groups, respectively (on the eighth day; Figure 1). The optimal doses were based on previous studies in rats. ${ }^{49,50}$

\section{Mechanical allodynia (von Frey test)}

Clinical studies have shown that most CM patients complain of allodynia after repeated migraine attacks. ${ }^{51,52}$ To explore

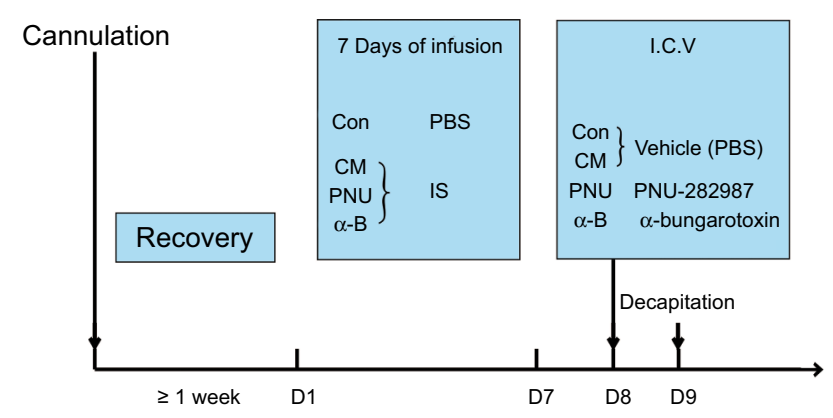

Figure I Schematic of the experimental design.

Notes: Cannulations were performed, and after at least I week of recovery, PBS or IS stimulation was applied to the dura through the affixed cannula. After the last stimulation (on the eighth day), the vehicle, PNU-282987 or $\alpha$-bungarotoxin was administered by intracerebroventricular injection to the different groups as illustrated. Twenty-four hours later (on the ninth day), the rats were decapitated. Abbreviations: $\alpha-B, \alpha$-bungarotoxin; CM, chronic migraine; Con, control; I.C.V, intracerebroventricular; IS, inflammatory soup; PNU, PNU-282987. the occurrence of allodynia in CM, we used the von Frey test to detect the mechanical threshold. Before testing, the rats were habituated to the testing apparatus $(30 \times 15 \times 17 \mathrm{~cm})$ for $15 \mathrm{~min}$. The von Frey test was performed on the hind paws ipsilateral to the surgery and at the midline of the forehead where the ophthalmic nerve distributed as described previously. ${ }^{53,54}$ A positive response for the von Frey test was recorded when the rat retracted its head or hind paw from the rigid tip. Mechanical allodynia was evaluated before IS or PBS infusion and $24 \mathrm{~h}$ after I.C.V injection of the vehicle, PNU-282987 or $\alpha$-bungarotoxin.

\section{Quantitative real-time polymerase chain reaction (PCR)}

The total RNA from the hippocampus tissue was isolated by using TRIzol reagent (Takara, Dalian, China). cDNA was amplified using the PrimeScript ${ }^{\mathrm{TM}}$ RT Reagent Kit (Takara) in 96-well PCR plates (Bio-Rad, Hercules, CA, USA). The PCR conditions were initiated with 1 cycle at $95^{\circ} \mathrm{C}$ for $30 \mathrm{~s}$, followed by 50 cycles of $95^{\circ} \mathrm{C}$ for $5 \mathrm{~s}$ and $50^{\circ} \mathrm{C}$ (for TNF- $\alpha$ and interleukin-1 beta [IL-1 $\beta$ ]) or $60^{\circ} \mathrm{C}$ (for $\alpha 7 \mathrm{nAChR}$ ) for $30 \mathrm{~s}$. The housekeeping gene glyceraldehyde-3-phosphate dehydrogenase (GAPDH) was used as a control.

The primer sequences were synthesized by Sangon Biotech Company (Shanghai, China). The primer sequences used in this study were as follows: 1 ) $\alpha 7 \mathrm{nAChR}$ (GenBank: NM_012832): F: 5'-GCAAAGAGCCATACCCAG-3'; R: 5'-CAGCAAGAATACCAGCAGAG-3'; 2) TNF- $\alpha$ (GenBank: D00475): F: 5'-CTTCAAGGGACAAGGCTG-3'; R:5'-GAGGCTGACTTTCTCCTG-3'; 3) IL-1 $\beta$ (GenBank: M98820): F: 5'-TACCTATGTCTTGCCCGTGGAG-3'; R: 5'-ATCATCCCACGAGTCACAGAGG-3'; 4) GAPDH (GenBank: M17701): F: 5'-TCCTGCACCACCAACTGCTTAG-3'; R: 5'-AGTGGCAGTGATGGCATGGACT-3'.

\section{Western blot (WB) analysis}

The proteins of the hippocampus were homogenized in radioimmunoprecipitation assay lysis buffer (sc-24948; Santa Cruz, Dallas, TX, USA) with phosphatase inhibitor (Boster, Wuhan, China) and protease inhibitor (Beyotime, Shanghai, China). We examined the expression of $\alpha 7 \mathrm{nAChR}$, TNF- $\alpha$, IL-1 $\beta$, CGRP, and p-JNK using Western blotting as previously described. ${ }^{55}$ The primary antibodies were $\alpha 7 \mathrm{nAChR}(1: 200$, sc-58607), TNF- $\alpha$ (1:500, sc-52B83), IL-1 (1:500, sc-12742), CGRP (1:500, sc-57053), p-JNK (1:500, sc-6254), and $\beta$-actin (1:4000, 20536-1-AP). The immunoreacted bands were visualized with a BeyoECL Plus Kit (P1008; Beyotime) and quantified with an imaging system (Fusion, Munich, Germany). 


\section{Immunofluorescence staining}

After anesthesia, the rats were perfused transcardially with chilled saline followed by $4 \%$ paraformaldehyde (PFA). The inner (medial) region of the temporal lobe (where the hippocampus is located) was subsequently removed and post-fixed overnight in $4 \% \mathrm{PFA}$ at $4^{\circ} \mathrm{C}$, then dehydrated with $20 \%$ sucrose for $24 \mathrm{~h}$ followed by $30 \%$ sucrose for $48 \mathrm{~h}$. Sections $20 \mu \mathrm{m}$ thick were cut with a cryostat (Leica, Wetzlar, Germany). The hippocampus sections were permeabilized with $0.3 \%$ Triton X-100 (Beyotime) at room temperature for $10 \mathrm{~min}$. Incubation was performed overnight at $4^{\circ} \mathrm{C}$ with the following primary antibodies: $\alpha 7 \mathrm{nAChR}(1: 200$, sc-58607), polyclonal goat anti-rat glial fibrillary acidic protein (GFAP, 1:100, ab49874), and ionized calcium binding adaptor molecule 1 (Iba1, 1:100, ab5076). After washing with PBS, the $\alpha 7 \mathrm{nAChR}$ sections were additionally incubated with goat anti-rat $\mathrm{Cy} 3$-conjugated secondary antibodies (1:6000, bs-0293G-HRP), while Iba1 sections were incubated with donkey anti-goat $\mathrm{Cy} 3$-conjugated secondary antibodies (A0502; Beyotime). Then, all sections were incubated with 4,6-diamino-2-phenyl indole (DAPI) staining solution (C1005; Beyotime) and analyzed with a confocal laser scanning fluorescence microscope (Olympus, Tokyo, Japan). Immunofluorescence staining was conducted in 3 animals per treatment group, with 3 representative hippocampus sections per animal. The number of positive cells was calculated as the mean of the aforementioned numbers.

\section{Statistical analysis}

The data are presented as the mean \pm SEM. Parametric data were analyzed by one-way analysis of variance and the Tukey post hoc method. The differences between 2 groups were compared using the unpaired $t$-test. SPSS 20.0 was used for statistical analysis. A value of $p<0.05$ was considered to represent statistically significant, while $p<0.01$ represented much more statistically significant.

\section{Results}

\section{Decrease in hind paw withdrawal and periorbital threshold after recurrent IS injection and the effects of $\alpha 7 \mathrm{nAChR}$}

Before the trials, no significant difference was observed in the mechanical threshold between the control and CM groups (Figure 2A). The paw withdrawal and periorbital threshold both decreased after the first infusion of IS with respect to the control $(p<0.05)$. After the second infusion, the differences became more significant $(p<0.01)$. These effects persisted until the final administration 1 week later.

To investigate the role of $\alpha 7 \mathrm{nAChR}$ on allodynia in $\mathrm{CM}$ rats, we used PNU-282987 ( $\alpha 7$ agonist) or $\alpha$-bungarotoxin
A
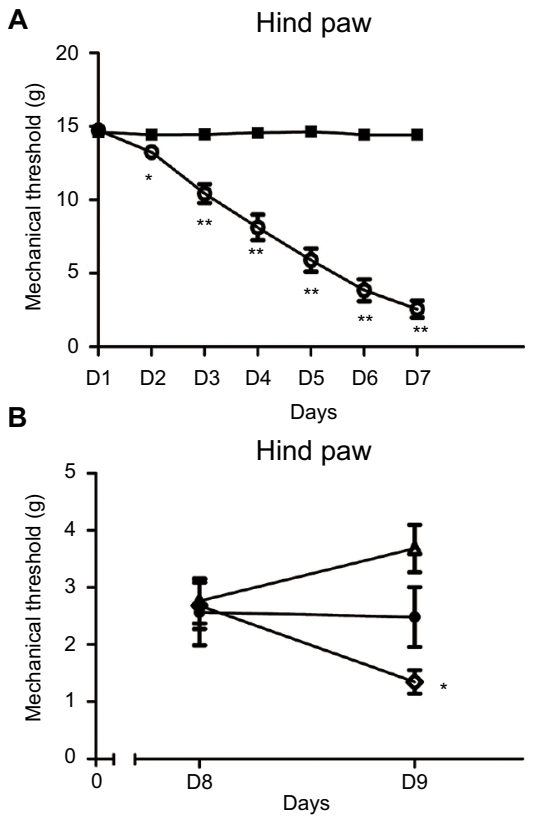
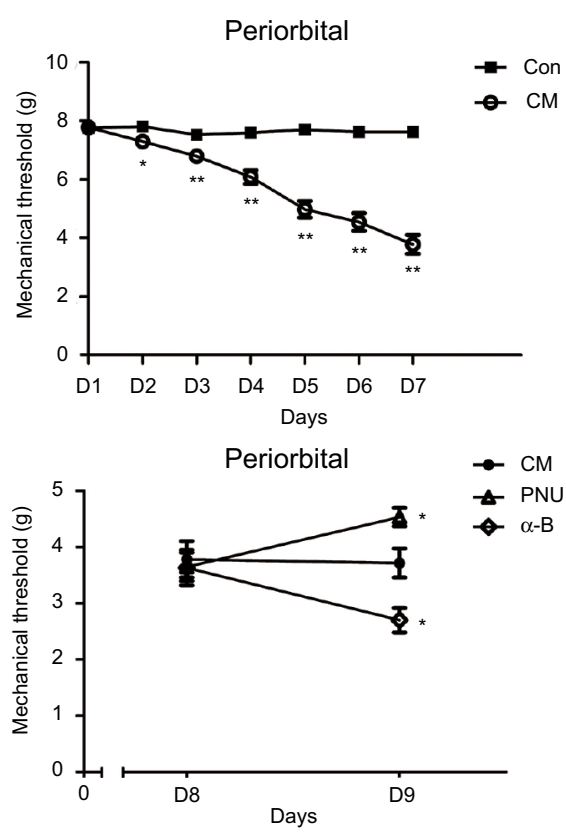

Figure 2 The decreased mechanical threshold in the CM group (relative to the control) was mitigated by PNU-282987 but aggravated by $\alpha$-bungarotoxin.

Notes: (A) The mechanical threshold of allodynia decreased in the CM group in hind paw stimulation $\left({ }^{*} p<0.05\right.$, ${ }^{* *} p<0.01$ versus control group). (B) The hind paw withdrawal and periorbital threshold were somewhat decreased after the intracerebroventricular injection of $\alpha$-bungarotoxin. The periorbital threshold was increased by PNU-282987. An increasing trend, but no significant difference, was observed between the CM and PNU-282987 groups (* $p>0.05$ versus CM group) ( $n=9$ per group).

Abbreviations: $\alpha-B, \alpha$-bungarotoxin; CM, chronic migraine; Con, control; PNU, PNU-282987. 
( $\alpha 7$ antagonist). Before I.C.V injection, no significant difference was observed in the CM, PNU-282987, and $\alpha$-bungarotoxin groups (Figure $2 \mathrm{~B}, p>0.05$ ). I.C.V injection of PNU-282987 exerted a protective effect against allodynia; the periorbital threshold improved significantly after $24 \mathrm{~h}(p<0.05)$, while the hind paw withdrawal threshold showed an ascending trend $(p>0.05)$. The administration of $\alpha$-bungarotoxin led to aggravation of both the hind paw withdrawal and periorbital threshold (Figure $2 \mathrm{~B}, p<0.05$ ).

\section{Recurrent IS injection decreased $\alpha 7 n A C h R$ expression in the CAI area of the hippocampus}

The expression of $\alpha 7 \mathrm{nAChR}$ in the control and CM groups was measured by PCR and Western blotting (Figure 3). Analysis showed that the protein level of $\alpha 7 \mathrm{nAChR}$ decreased significantly after the repeated administration of IS $(* * p<0.01$, Figure $3 \mathrm{~A})$. To investigate the cause, we
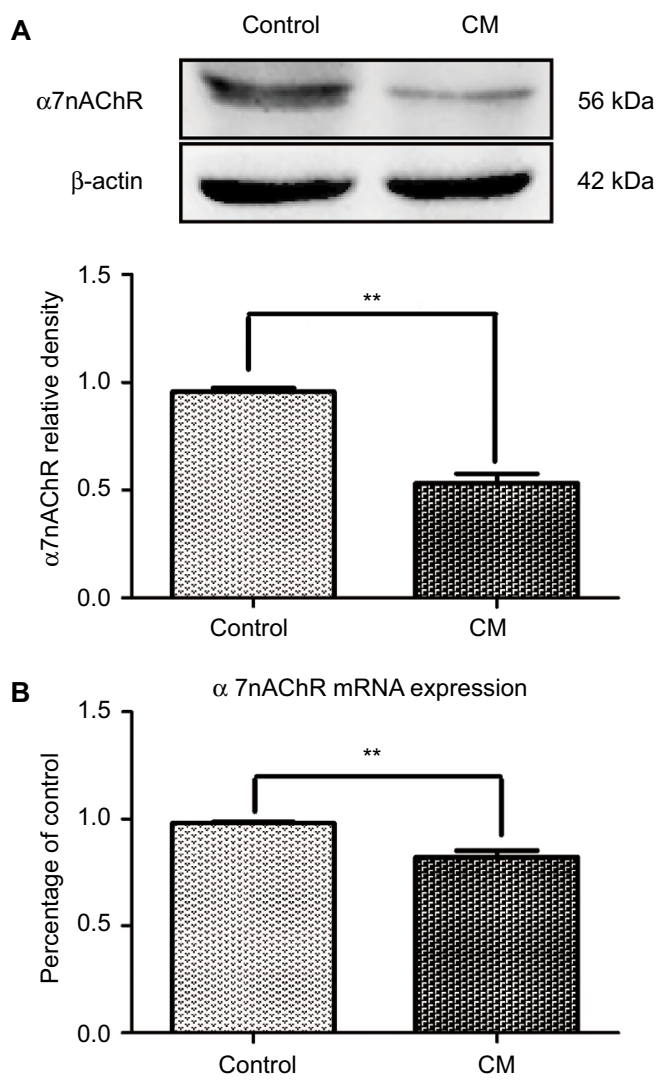

Figure 3 The expression of $\alpha 7 n A C h R$ decreased in the hippocampus of CM rats. Notes: The level of $\alpha 7 n A C h R$ in the hippocampus was determined by WB and PCR. The recurrent injection of IS decreased $\alpha 7 n A C h R$ expression significantly at both the protein $(\mathbf{A})$ and the mRNA levels $(\mathbf{B})(* * p<0.0 \mathrm{I}, \mathrm{n}=6$ per group).

Abbreviations: $\alpha 7 \mathrm{nAChR}, \alpha 7$ nicotinic acetylcholine receptor; $\mathrm{CM}$, chronic migraine; IS, inflammatory soup; PCR, polymerase chain reaction; WB, Western blot. performed mRNA-level verification and found that the mRNA level of $\alpha 7 \mathrm{nAChR}$ was also significantly reduced $\left({ }^{* *} p<0.01\right.$, Figure $\left.3 \mathrm{~B}\right)$. These data indicated that recurrent IS injection significantly decreased $\alpha 7 \mathrm{nAChR}$ expression in the hippocampus.

\section{Expression of $\alpha 7 n A c h R$ in hippocampal CAI, CA3, and dentate gyrus regions}

The distribution of $\alpha 7 \mathrm{nAChR}$ was most in hippocampus, especially CA1, CA3, and dentate gyrus layers. So we chose these regions to study $\alpha 7 \mathrm{nAChR}$ in CM. PNU-282987 (agonist of $\alpha 7$ ) and $\alpha$-bungarotoxin (antagonist of $\alpha 7$ ) were performed respectively and immunofluorescence staining analyses were used to explore the $\alpha 7 \mathrm{nAChR}$ expression in the 3 hippocampal areas of the 4 groups (Figure 4 ). The $\alpha 7 n A C h R$ was significantly decreased in hippocampal CA1, CA3, and DG areas in the $\mathrm{CM}$ group than the control. The expression of $\alpha 7 \mathrm{nAChR}$ in hippocampal CA1 and CA3 regions was increased after administration of PNU-282987 (**p<0.01, Figure 4C); however, there were no changes in DG region. There was no statistical significance between the $\mathrm{CM}$ and $\alpha$-bungarotoxin groups in all the 3 regions. It indicated that activated $\alpha 7 \mathrm{nAChR}$ in hippocampal CA1 and CA3 might be mainly responsible for reducing inflammation in central neuroimmune.

\section{Effects of $\alpha 7 n A c h R$ on the activation of astrocytes and microglia in the hippocampal CAI and CA3 areas in CM rats}

The astrocytes and microglia were significantly activated in the CM group in both hippocampal CA1 and CA3 regions, showing swollen cell bodies and synaptic coarsening (Figure 5). In contrast, their morphology in the control group showed smaller cell bodies. In CA1 area, the number of Iba-1-positive cells decreased after the administration of PNU-282987 (63.94 \pm 6.31 versus CM group, Figure 5A) and showed a decreasing trend with respect to the control group $(p>0.05)$. The numbers of GFAP-labeled cells

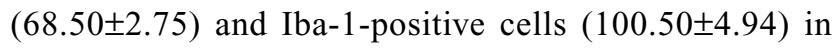
the CM group were significantly higher than those in the control group (24.50 \pm 4.15 and $80.41 \pm 3.13$, respectively). After the administration of PNU-282987, the number of GFAP-labeled cells $(26.00 \pm 2.05)$ was lower than that in the CM group but was still higher than that in the control group, indicating that the activation of astrocytes was partially inhibited. The $\alpha$-bungarotoxin group also showed 
A
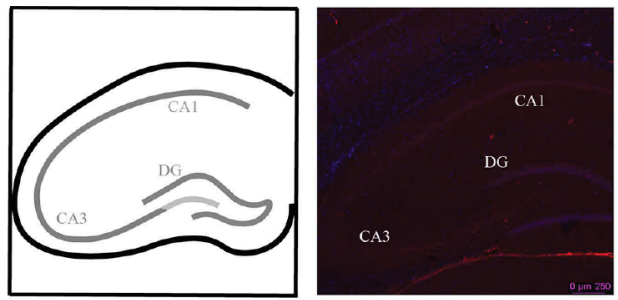

B
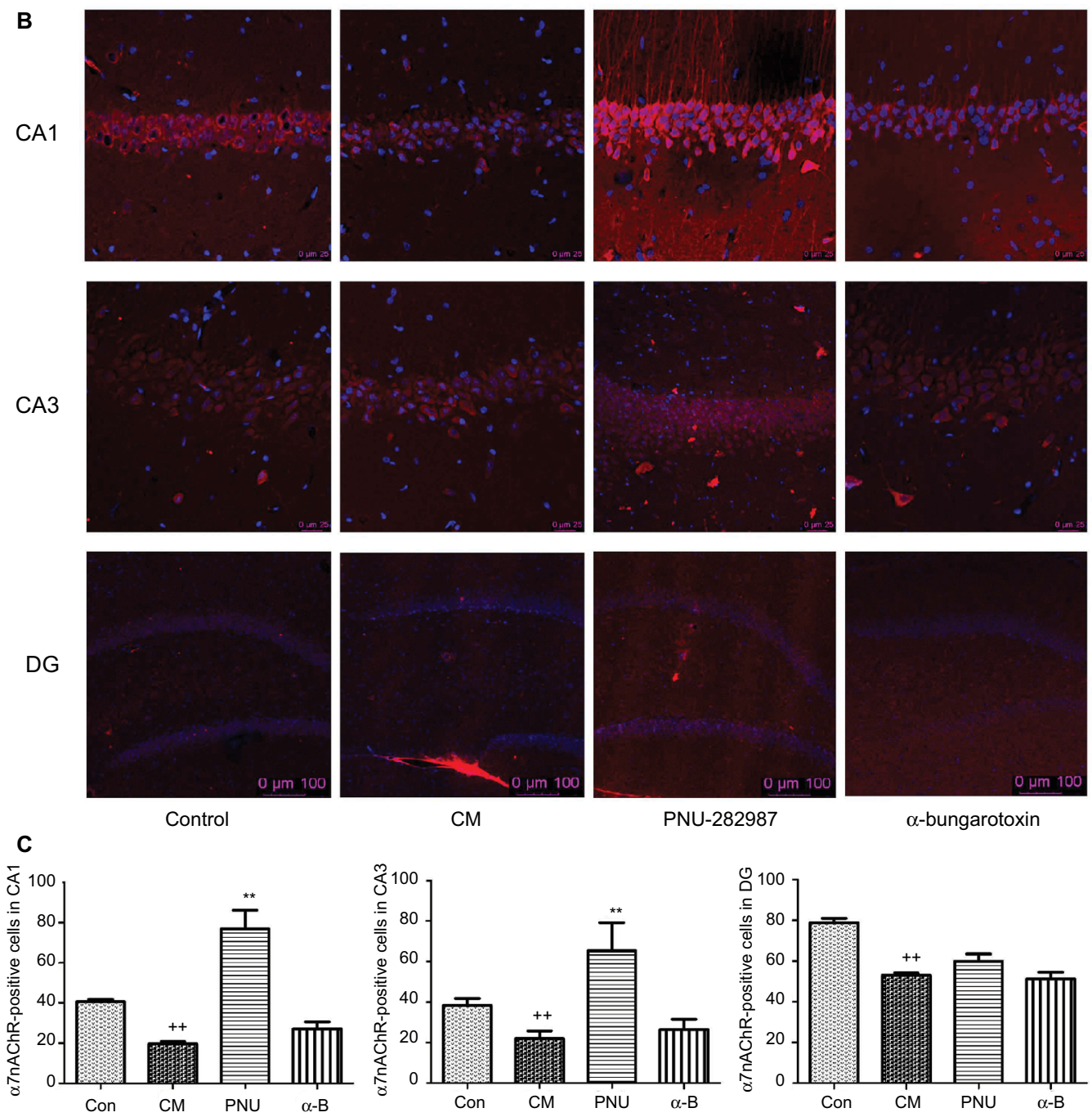

$\mathrm{CM}$

PNU-282987

$\alpha$-bungarotoxin
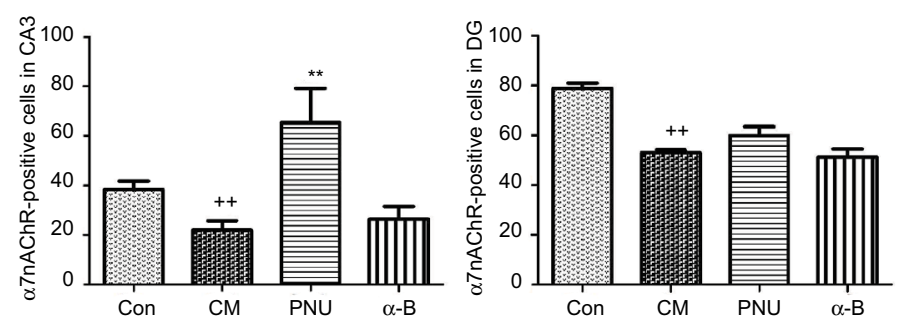

Figure 4 The distribution of $\alpha 7 n A C h R$ in the hippocampus in all groups.

Notes: (A) Schematic diagram of the hippocampus. (B) The expression of $\alpha 7 n A C h R$ in hippocampal CAI, CA3, and DG areas. (C) The average numbers of $\alpha 7 n A C h R$ were significantly decreased in hippocampal CAI, CA3, and DG areas in the CM group. PNU-282987 activated the $\alpha 7 n A C h R$ in both CAI and CA3 regions, but not in DG region. There were no significant differences between the $C M$ and $\alpha$-bungarotoxin groups in all the 3 regions $\left({ }^{+} p<0.01\right.$ versus control, ${ }^{* *} p<0.01$ versus $\left.C M\right)$. All data were expressed as the mean \pm SEM, $n=3$ per group, bar: $250 \mu \mathrm{m}$ of (A), $25 \mu \mathrm{m}$ in CAI and CA3 of (B), $100 \mu \mathrm{m}$ in DG of (B).

Abbreviations: $\alpha 7 n A C h R, \alpha 7$ nicotinic acetylcholine receptor; $\alpha$-B, $\alpha$-bungarotoxin; CM, chronic migraine; Con, control; DG, dentate gyrus; PNU, PNU-282987; SEM, standard error of the mean.

activation of astrocytes and microglia in the hippocampus CA1 area, but the difference with respect to the CM group was not statistically significant. In CA3 area, the numbers of GFAP-positive cells were also partially inhibited by PNU-282987, but Iba-1-positive cells were shown to be the statistically significant compared with the control group $(p<0.01$, Figure 5B).

\section{Effects of PNU-282987 or} $\alpha$-bungarotoxin on the expression of TNF- $\alpha$, IL-I $\beta$, and CGRP in the hippocampus

As shown in Figure 6A, TNF- $\alpha$ and IL-1 $\beta$ were significantly elevated in the CM group $(p<0.01)$, while PNU-282987 
A Iba1
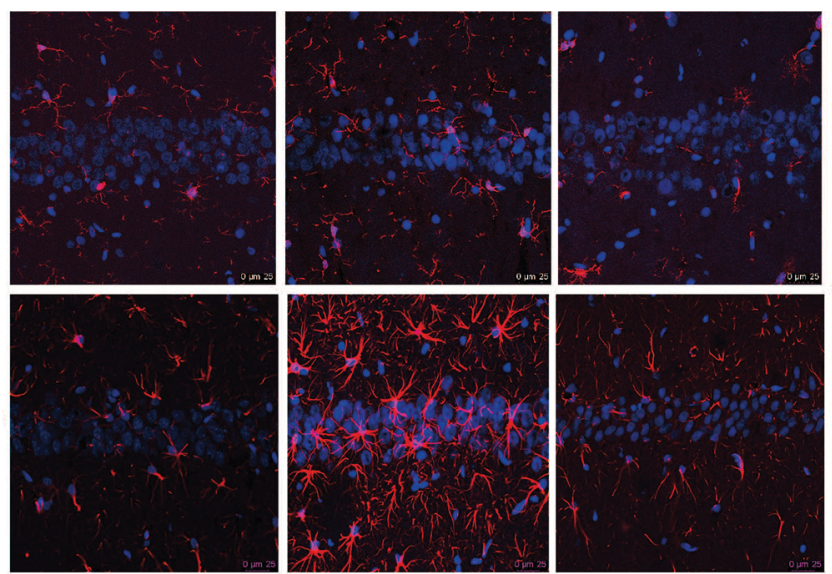

CM

B

lba1
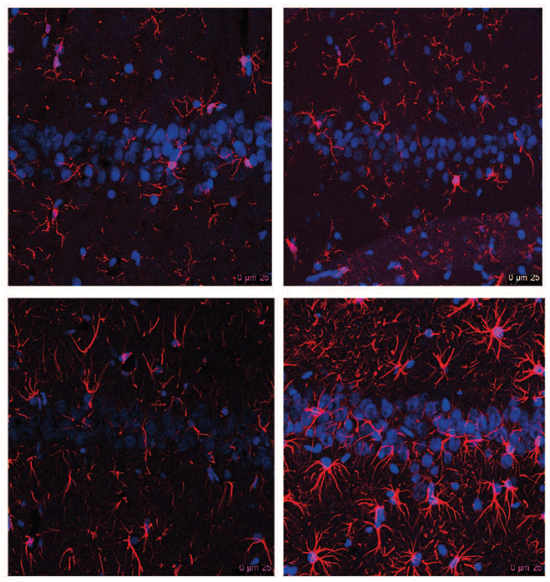

CM

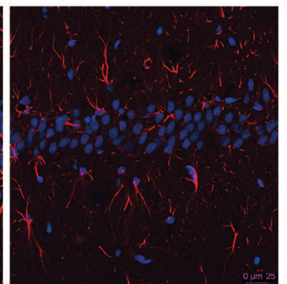

PNU
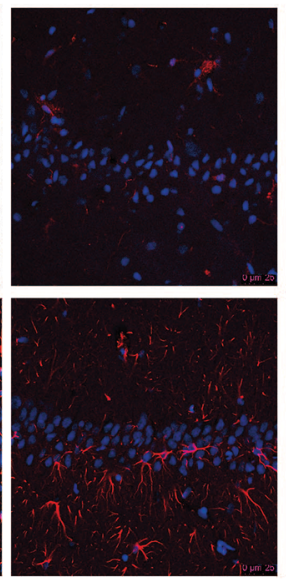

PNU

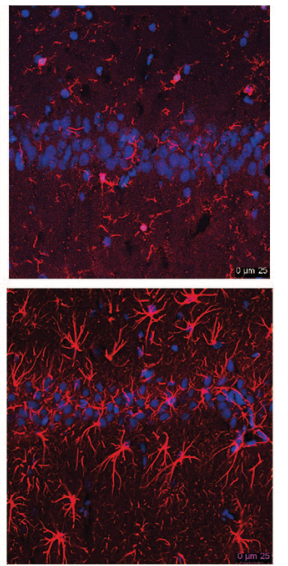

$\alpha-B$
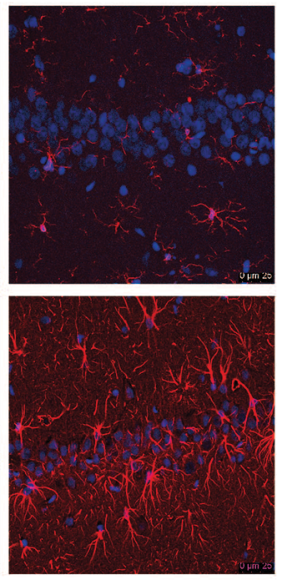

$\alpha-B$
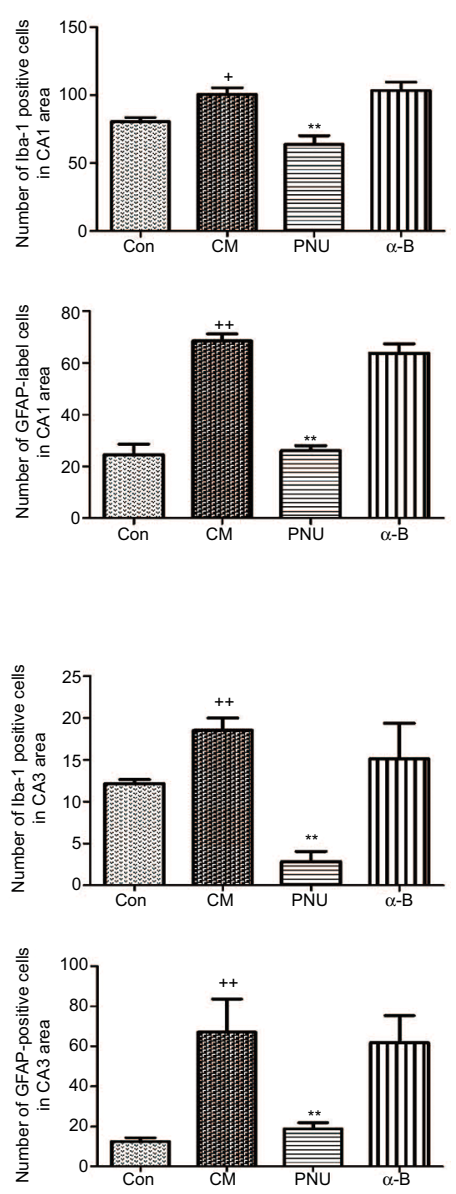

Figure 5 The morphology of astrocytes and microglia in the hippocampus CAI and CA3 areas in all groups.

Notes: (A) In the CM and $\alpha$-bungarotoxin groups, the astrocytes and microglia exhibited swollen cell bodies and synaptic coarsening, while the morphology of the control group was small cell bodies. In the PNU-282987 group, the morphology of the labeled-activated cells showed less activation, with fewer numbers and smaller cell bodies. (B) The average numbers of astrocytes and microglia were significantly increased in the CM group and were both suppressed by PNU-282987. The GFAP-labeled cells and Ibal-positive cells showed no significant differences between the $C M$ and $\alpha$-bungarotoxin groups $\left({ }^{+} p<0.05\right.$ and ${ }^{+} p<0.01$ versus control, ${ }^{* *} p<0.0$ I versus $\left.C M\right)$. All data were expressed as the mean \pm SEM, $n=3$ per group, bar: $25 \mu \mathrm{m}$.

Abbreviations: $\alpha-B$, $\alpha$-bungarotoxin; CM, chronic migraine; Con, control; GFAP, goat anti-rat glial fibrillary acidic protein; Ibal, ionized calcium binding adaptor molecule I; PNU, PNU-282987; SEM, standard error of the mean.

significantly decreased the elevated levels $(p<0.01)$. In contrast, $\alpha$-bungarotoxin aggravated the expression of IL-1 $\beta$ $(p<0.01)$ and showed a tendency to increase TNF- $\alpha(p>0.05)$. We also observed the increased mRNA expression levels of TNF- $\alpha$ and IL-1 $\beta$ (Figure 6B).The administration of PNU282987 showed an inhibitory effect on TNF- $\alpha(p<0.05)$ and IL-1 $\beta(p<0.01) . \alpha$-bungarotoxin increased the mRNA expression of TNF- $\alpha(p<0.05)$ and IL-1 $(p<0.01)$. These results demonstrated that the IS-induced increase in proinflammatory cytokines could be regulated by $\alpha 7 \mathrm{nAChR}$.

We observed a substantial increase in CGRP protein in the hippocampus in $\mathrm{CM}$ rats $(p<0.01$, Figure $6 \mathrm{C})$. This increase was abolished by the administration of PNU-282987 $(p<0.01)$ and aggravated by the administration of $\alpha$-bungarotoxin $(p<0.01)$.

\section{Effects of $\alpha 7 n A C h R$ agonist and antagonist administration on $\mathrm{P}-\mathrm{JNK}$ - MAPK expression in CM rats}

To verify whether phosphorylated JNK participates in CM pathophysiology and whether its regulation is related to $\alpha 7 \mathrm{nAChR}$, we examined the expression of the p-JNK protein using WB analysis. The results revealed that the level of $\mathrm{p}-\mathrm{JNK}$ was increased in the CM group and suppressed by PNU-282987 ( $p<0.01$, Figure 7). No significant differences were observed between the $\mathrm{CM}$ and $\alpha$-bungarotoxin groups.

\section{Discussion}

In this study, we verified that $\alpha 7 \mathrm{nAChR}$ in the hippocampal microglia and astrocytes plays a role in CM pathophysiology. 
A
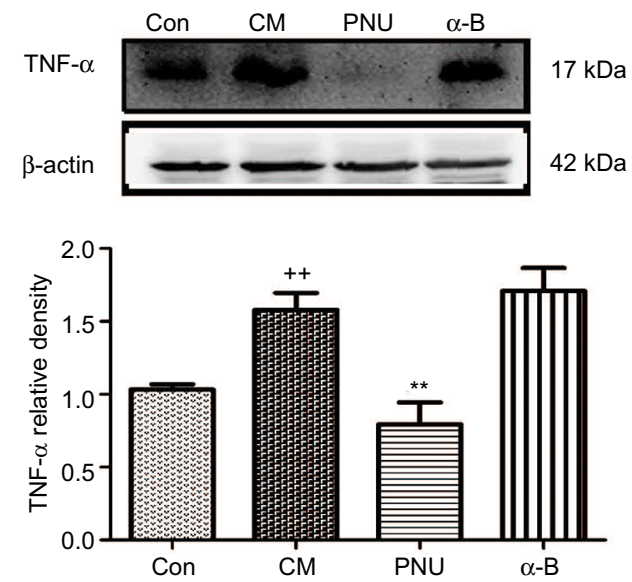

B

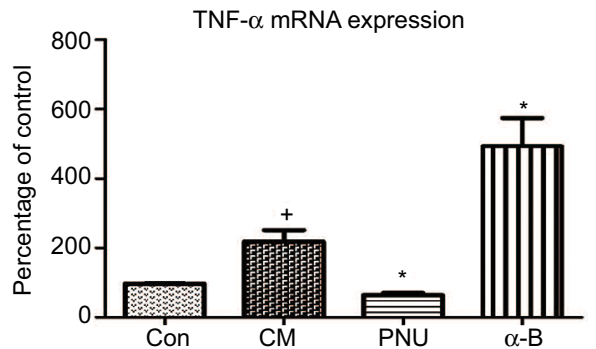

C

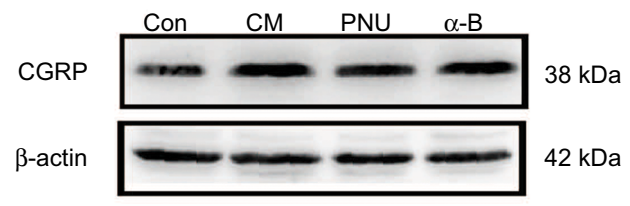

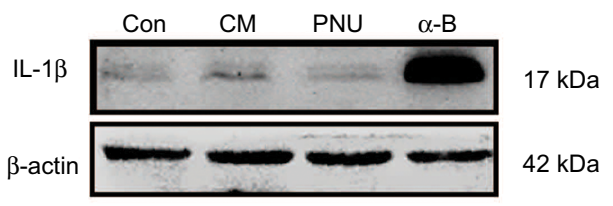
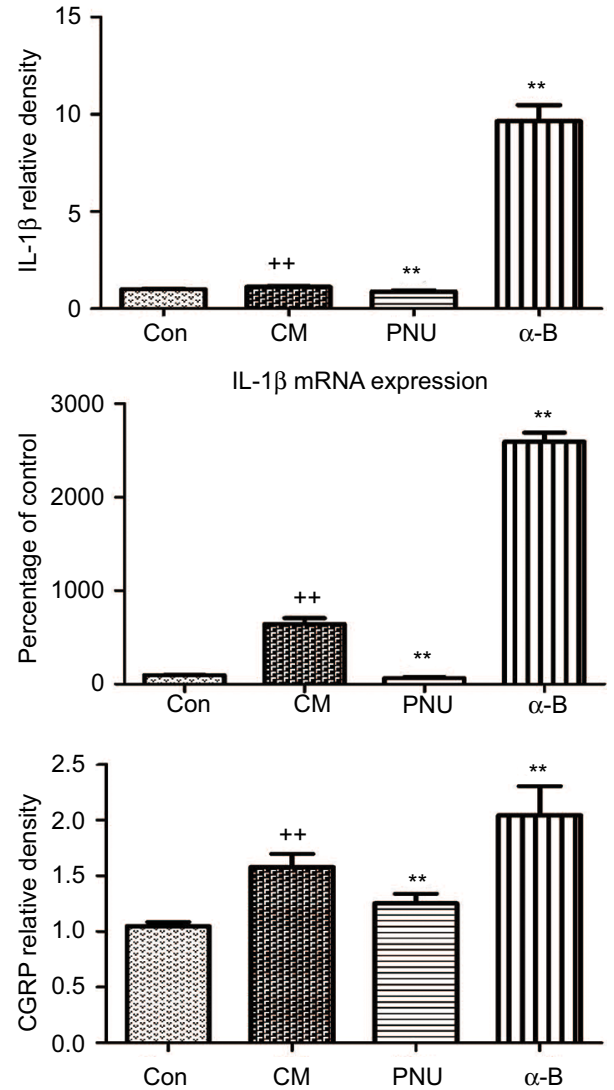

Figure 6 WB and PCR data showed dynamic changes in TNF- $\alpha$, IL-I $\beta$, and CGRP.

Notes: (A) The IS-induced increases in TNF- $\alpha$ and IL-I $\beta$ were both significantly inhibited by PNU-282987 $\left({ }^{++} p<0.0\right.$ I versus control, ${ }^{* *} p<0.0$ I versus CM). In the $\alpha$-bungarotoxin-treated group, TNF- $\alpha$ showed a tendency to increase compared with the value in the CM group $(p>0.05)$, while IL-I $\beta$ showed a significant increase $(p<0.0 \mathrm{I})$. (B) mRNA data for TNF- $\alpha$ and IL-I $\beta\left({ }^{+} p<0.05\right.$ and ${ }^{++} p<0.0$ I versus control; ${ }^{*} p<0.05$ and ${ }^{* *} p<0.0$ I versus CM). (C) The IS-induced increase in CGRP protein expression was significantly inhibited after PNU-282987 administration. In contrast, $\alpha$-bungarotoxin stimulated a further increase in CGRP expression $\left({ }^{++} p<0.01\right.$ versus control, $* * p<0.01$ versus $C M$ ). All data are expressed as the mean \pm SEM, $n=6$ per group.

Abbreviations: $\alpha-B, \alpha$-bungarotoxin; CGRP, calcitonin gene-related peptide; CM, chronic migraine; Con, control; IS, inflammatory soup; PCR, polymerase chain reaction; PNU, PNU-282987; WB, Western blot.

Our current data indicate the following: 1) $\alpha 7 \mathrm{nAChR}$ expression was decreased in CM rats; 2) repeated epidural injections of IS accelerated TNF- $\alpha$ and IL- $1 \beta$ expression and promoted the neurogenic inflammation that is the core reason for CM; 3) $\alpha 7 n A C h R$ activation decreased the expression of proinflammatory cytokines and induced analgesic effects in CM; and 4) the activation of microglia and astrocytes in CM was suppressed by the I.C.V injection of PNU-282987.

Previous studies have suggested that $\alpha 7 \mathrm{nAChRs}$ are expressed predominantly in hippocampal GABAergic interneurons, ${ }^{56,57}$ as well as microglial cells ${ }^{58}$ and astrocytes. ${ }^{59}$ Their impaired function was attributed partly to the decreased expression of $\alpha 7 \mathrm{nAChRs} .{ }^{56}$ Mice with $\alpha 7 \mathrm{nAChR}$ mutation (knockout $[\mathrm{KO}]$ ) displayed significantly lower paw withdrawal latency in chronic inflammatory and neuropathic pain, while its complementary $\alpha 7$ hypersensitive mice (knock in $[\mathrm{KI}])$ exhibited the opposite effect. ${ }^{60}$ Intraperitoneal administration of $\alpha 7 \mathrm{nAChR}$-positive allosteric modulator could also reduce allodynia in an inflammatory pain model ${ }^{61}$ These results suggested that the decrease in $\alpha 7 \mathrm{nAChR}$ was a cause of allodynia in neuropathic pain. Our study extended these findings by demonstrating the downregulated expression of $\alpha 7 \mathrm{nAChR}$ in CM. To the best of our knowledge, this study is the first to examine $\alpha 7 \mathrm{nAChR}$ expression in a rat CM model. 
Clinical trials showed increased gene expression levels ${ }^{5}$ and serum levels ${ }^{62-65}$ of pro-inflammatory cytokines in the migraine attack group, which indicated the pivotal role of neuroinflammation in migraine pathogenesis. The recurrent epidural administration of IS resulted in allodynia-like effects and pro-inflammatory cytokine expression, which had been considered features of $\mathrm{CM} .{ }^{66}$ The results of our study agreed with the literature in this respect. In this study, a parallel increase in TNF- $\alpha$ and IL- $1 \beta$ was observed after the recurrent epidural administration of IS. TNF- $\alpha$ and IL- $1 \beta$ were also both significantly suppressed after the I.C.V injection of PNU282987. In the behavioral experiment, the allodynia induced by CM was alleviated after the PNU-282987 intervention. Therefore, we speculated that $\alpha 7 \mathrm{nAChR}$ expression might correlate with CM allodynia. Our study also demonstrated that the elevation of pro-inflammatory cytokines enhanced the CGRP-induced central sensitization. An inflammatory pain model showed that the activated $\alpha 7 \mathrm{nAChR}$ induced antiallodynic responses through modulate micro glial activation in hippocampus. ${ }^{67}$ Furthermore, previous results also suggested that microglial activation preceded astrocytic activation and that astrocytes maintained the hypersensitivity. ${ }^{9}$ Our study provided additional supporting evidence that microglia and astrocytes in the CNS mediated the progression of CM. The upregulation of microglia and astrocytes in $\mathrm{CM}$ rats was reversed by PNU-282987. Pro-inflammatory cytokines were also suppressed, inducing analgesic effects in CM.
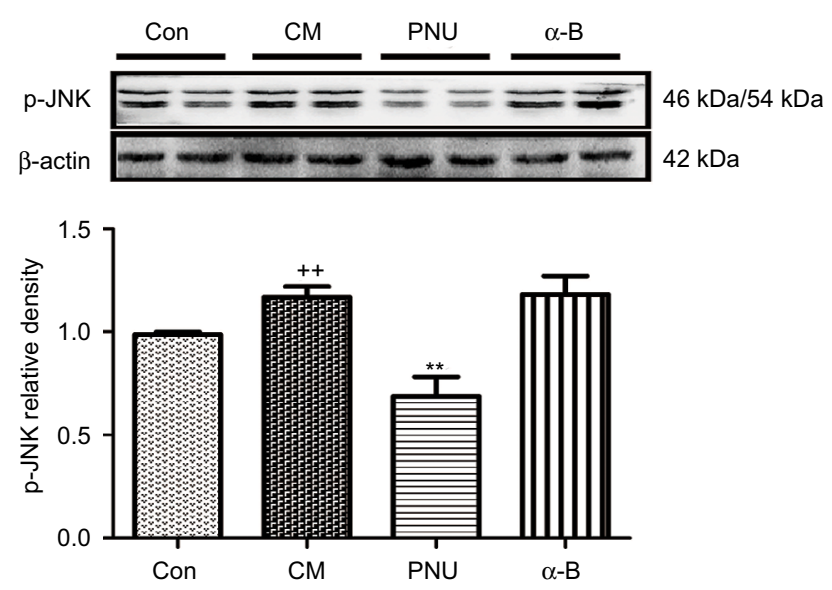

Figure $7 \mathrm{Gel}$ panels of hippocampus tissue in control, CM, PNU-282987, and $\alpha$-bungarotoxin groups using WB. $\beta$-Actin was used as a loading control.

Notes: The relative protein level of $\mathrm{P}-\mathrm{JNK}$ was increased in CM rats and was suppressed by PNU-282987. A higher protein level of p-JNK was also observed after the administration of $\alpha$-bungarotoxin, but the difference from the level in the CM group was not statistically significant $\left({ }^{++} p<0.01\right.$ versus control, ${ }^{* *} p<0.01$ versus CM). All data are expressed as the mean \pm SEM, $n=6$ per group).

Abbreviations: $\alpha-B, \alpha$-bungarotoxin; CM, chronic migraine; Con, control; p-JNK, phosphorylated c-Jun N-terminal kinase; PNU, PNU-282987; WB, Western blot; SEM, standard error of the mean.
Previous studies implicated the JNK-MAPK pathway in the development of glial activation. ${ }^{68-70}$ As one of the most important members of the MAPK family, JNK was also found to be activated in neuropathic pain..$^{71-73}$ Our data illustrated that the alleviation of activated glia and pain behavior was ameliorated by the activation of $\alpha 7 \mathrm{nAChR}$. Therefore, we hypothesized that the effect might proceed through this complex downstream signaling pathway. The increased expression of phosphorylated JNK in CM rats was significantly inhibited by the I.C.V injection of PNU-282987, which was consistent with previous reports. ${ }^{74}$ Furthermore, downregulation of TNF- $\alpha$ and IL-1 $\beta$ was observed (Figure 8 ). There was no significant difference in $\mathrm{p}-\mathrm{JNK}$ expression between the $\alpha$-bungarotoxin and CM groups, it might be because of the limited timeframe or the small doses.

This study is entirely novel in that it investigates the previously unmeasured $\alpha 7 \mathrm{nAChR}$ level in a rat model of $\mathrm{CM}$. The levels of activated astrocytes and microglia and inflammatory cytokine expression have also been compared to illuminate the mechanism of $\mathrm{CM}$ pathophysiology. Future studies using chronic administration regimens would also be of interest to determine whether the long-term activation of $\alpha 7 \mathrm{nAChR}$ results in differential effects in CM.

\section{Conclusion}

The activation of $\alpha 7 \mathrm{nAChR}$ inhibits the activation of astrocytes and microglia in CM through the p-JNK-MAPK signaling pathway. Increased levels of TNF- $\alpha$, IL- $1 \beta$, and CGRP in the nociceptive network are related to the pathophysiological dysfunctions in $\mathrm{CM}$ and $\alpha 7 \mathrm{nAChR}$ activation could inhibit

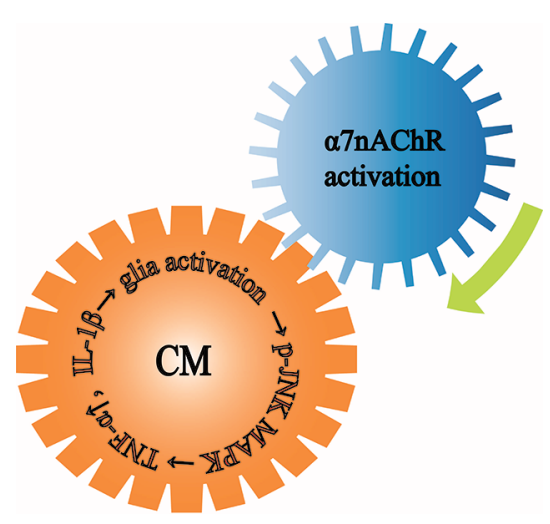

Figure 8 The theme of this article.

Notes: Microglia and astrocytes in the CNS mediated the development of CM. Microglia and astrocytes were activated in CM, they released TNF- $\alpha$ and IL-I $\beta$ through the downstream P-JNK-MAPK signaling pathway to further aggravate CM. The activation of $\alpha 7 \mathrm{nAChR}$ alleviated the activated glia and ameliorated the pain. Abbreviations: $\alpha 7 \mathrm{nAChR}, \alpha 7$ nicotinic acetylcholine receptor; CM, chronic migraine; CNS, central nervous system; IL, interleukin; MAPK, mitogen-activated protein kinase; $\mathrm{P}$-JNK, phosphorylated c-Jun $\mathrm{N}$-terminal kinase.; TNF, tumor necrosis factor. 
their expression. With this work, we aim to contribute to the development of a potential therapeutic target in CM.

\section{Acknowledgments}

The authors would like to thank Tiwei Fu for his work on the confocal laser scanning fluorescence tests. Special thanks are due to the Laboratory Research Center of the First Affiliated Hospital of Chongqing Medical University for the animal husbandry support. This study was supported by the National Natural Science Foundation of China (no. 81671092) and the Natural Science Foundation Project of Chongqing Science and Technology Commission (no. cstc2013jjB10009).

\section{Disclosure}

The authors report no conflicts of interest in this work.

\section{References}

1. Bigal ME, Rapoport AM, Lipton RB, Tepper SJ, Sheftell FD. Assessment of Migraine Disability Using the Migraine Disability Assessment (MIDAS) questionnaire: a comparison of chronic migraine with episodic migraine. Headache. 2003;43(4):336-342.

2. Rozen T, Swidan SZ. Elevation of CSF tumor necrosis factor alpha levels in new daily persistent headache and treatment refractory chronic migraine. Headache. 2007;47(7):1050-1055.

3. Pusic KM, Pusic AD, Kemme J, Kraig RP. Spreading depression requires microglia and is decreased by their M2a polarization from environmental enrichment. Glia. 2014;62(7):1176-1194.

4. Domínguez C, Vieites-Prado A, Pérez-Mato M, et al. Role of adipocytokines in the pathophysiology of migraine: a cross-sectional study. Cephalalgia. 2017;35(5):904-911.

5. Perry CJ, Blake P, Buettner C, et al. Upregulation of inflammatory gene transcripts in periosteum of chronic migraineurs: implications for extracranial origin of headache. Ann Neurol. 2016;79(6):1000-1013.

6. Aurora SK. Spectrum of illness: understanding biological patterns and relationships in chronic migraine. Neurology. 2009;72(5 Suppl):S8-S13.

7. Zhao J, Brooks DM, Lurie DI. Lipopolysaccharide-activated SHP1-deficient motheaten microglia release increased nitric oxide, TNFalpha, and IL-1beta. Glia. 2006;53(3):304-312.

8. Akama KT, Van Eldik LJ. $\beta$-amyloid stimulation of inducible nitricoxide synthase in astrocytes is interleukin-1 $\beta$ - and Tumor Necrosis Factor- $\alpha(\mathrm{TNF} \alpha)$-dependent, and involves a TNF $\alpha$ receptor-associated factor- and NFKB-inducing kinase-dependent signaling mechanism. J Biol Chem. 2000;275(11):7918-7924.

9. Raghavendra V, Tanga FY, DeLeo JA. Complete freunds adjuvantinduced peripheral inflammation evokes glial activation and proinflammatory cytokine expression in the CNS. Eur J Neurosci. 2004;20(2): 467-473.

10. Shibata M, Suzuki N. Exploring the role of microglia in cortical spreading depression in neurological disease. J Cereb Blood Flow Metab. 2017;37(4):1182-1191.

11. Ghaemi A, Alizadeh L, Babaei S, et al. Astrocyte-mediated inflammation in cortical spreading depression. Cephalalgia. 2018:38(4):626-638.

12. Stalnikowicz R. Nicotine gum withdrawal and migraine headaches. Eur $J$ Emerg Med. 2006;13(4):247-248.

13. Hoover DB. Cholinergic modulation of the immune system presents new approaches for treating inflammation. Pharmacol Ther. 2017;179:1-16.

14. Nicolodi M, Galeotti N, Ghelardini C, Bartolini A, Sicuteri F. Central cholinergic challenging of migraine by testing second-generation anticholinesterase drugs. Headache. 2002;42(7):596-602.
15. Wang $\mathrm{H}, \mathrm{Yu} \mathrm{M}$, Ochani $\mathrm{M}$, et al. Nicotinic acetylcholine receptor a7 subunit is an essential regulator of inflammation. Nature. 2003;421(6921):384-388.

16. Dajas-Bailador FA, Lima PA, Wonnacott S. The a7 nicotinic acetylcholine receptor subtype mediates nicotine protection against NMDA excitotoxicity in primary hippocampal cultures through a $\mathrm{Ca} 2+$ dependent mechanism. Neuropharmacology. 2000;39(13):2799-2807.

17. Stevens TR, Krueger SR, Fitzsimonds RM, Picciotto MR. Neuroprotection by nicotine in mouse primary cortical cultures involves activation of calcineurin and L-type calcium channel inactivation. J Neurosci. 2003;23(31):10093-10099.

18. Parada E, Egea J, Buendia I, et al. The microglial alpha7-acetylcholine nicotinic receptor is a key element in promoting neuroprotection by inducing heme oxygenase-1 via nuclear factor erythroid-2-related factor 2. Antioxid Redox Signal. 2013;19(11):1135-1148.

19. Frasch MG, Szynkaruk M, Prout AP, et al. Decreased neuroinflammation correlates to higher vagus nerve activity fluctuations in near-term ovine fetuses: a case for the afferent cholinergic anti-inflammatory pathway? J Neuroinflammation. 2016;13(1):103.

20. Shi S, Liang D, Bao M, et al. Gx-50 inhibits neuroinflammation via alpha $7 \mathrm{nAChR}$ activation of the JAK2/STAT3 and PI3K/AKT pathways. J Alzheimers Dis. 2016;50(3):859-871.

21. Loram LC, Harrison JA, Chao L, et al. Intrathecal injection of an alpha seven nicotinic acetylcholine receptor agonist attenuates gp120-induced mechanical allodynia and spinal pro-inflammatory cytokine profiles in rats. Brain Behav Immun. 2010;24(6):959-967.

22. Bagdas D, Wilkerson JL, Kulkarni A, et al. The $\alpha 7$ nicotinic receptor dual allosteric agonist and positive allosteric modulator GAT107 reverses nociception in mouse models of inflammatory and neuropathic pain. Br J Pharmacol. 2016;173(16):2506-2520.

23. Rowley TJ, McKinstry A, Greenidge E, Smith W, Flood P. Antinociceptive and anti-inflammatory effects of choline in a mouse model of postoperative pain. Br J Anaesth. 2010;105(2):201-207.

24. Guo JR, Wang H, Jin XJ, Jia DL, Zhou X, Tao Q. Effect and mechanism of inhibition of PI3K/Akt/mTOR signal pathway on chronic neuropathic pain and spinal microglia in a rat model of chronic constriction injury. Oncotarget. 2017;8(32):52923-52934.

25. Kalashnyk O, Lykhmus O, Oliinyk O, Komisarenko S, Skok M. alpha7 Nicotinic acetylcholine receptor-specific antibody stimulates interleukin-6 production in human astrocytes through p38-dependent pathway. Int Immunopharmacol. 2014;23(2):475-479.

26. Morioka N, Tokuhara M, Nakamura Y, et al. Primary cultures of rat cortical microglia treated with nicotine increases in the expression of excitatory amino acid transporter 1 (GLAST) via the activation of the 7 nicotinic acetylcholine receptor. Neuroscience. 2014;258:374-384.

27. Sun R, Zhang W, Bo J, et al. Spinal activation of alpha7-nicotinic acetylcholine receptor attenuates posttraumatic stress disorderrelated chronic pain via suppression of glial activation. Neuroscience. 2017;344:243-254.

28. Zhang Q, Lu Y, Bian H, Guo L, Zhu H. Activation of the $\alpha 7$ nicotinic receptor promotes lipopolysaccharide-induced conversion of M1 microglia to M2. Am J Transl Res. 2017;9(3):971-985.

29. Liu MG, Chen J. Roles of the hippocampal formation in pain information processing. Neurosci Bull. 2009;25(5):237-266.

30. Schwedt TJ, Chong CD, Chiang CC, Baxter L, Schlaggar BL, Dodick DW. Enhanced pain-induced activity of pain-processing regions in a case-control study of episodic migraine. Cephalalgia. 2014;34(12):947-958.

31. Liu J, Lan L, Li G, et al. Migraine-related gray matter and white matter changes at a 1-year follow-up evaluation. J Pain. 2013;14(12):1703-1708.

32. Maleki N, Becerra L, Brawn J, McEwen B, Burstein R, Borsook D. Common hippocampal structural and functional changes in migraine. Brain Struct Funct. 2013;218(4):903-912.

33. Coppola G, Petolicchio B, Di Renzo A, et al. Cerebral gray matter volume in patients with chronic migraine: correlations with clinical features. J Headache Pain. 2017;18(1):115. 
34. Rubboli F, Court JA, Sala C, et al. Distribution of nicotinic receptors in the human hippocampus and thalamus. Eur J Neurosci. 1994;6(10):1596-1604.

35. Baddick CG, Marks MJ. An autoradiographic survey of mouse brain nicotinic acetylcholine receptors defined by null mutants. Biochem Pharmacol. 2011;82(8):828-841.

36. Fabian-Fine R, Skehel P, Errington ML, et al. Ultrastructural distribution of the $\alpha 7$ nicotinic acetylcholine receptor subunit in rat hippocampus. J Neurosci. 2001;21(20):7993-8003.

37. Garcia-Rates S, Camarasa J, Sanchez-Garcia AI, Gandía L, Escubedo E, Pubill D. The effects of 3,4-methylenedioxymethamphetamine (MDMA) on nicotinic receptors: intracellular calcium increase, calpain/caspase 3 activation, and functional upregulation. Toxicol Appl Pharmacol. 2010;244(3):344-353.

38. Schedel A, Thornton S, Schloss P, Klüter H, Bugert P. Human platelets express functional alpha7-nicotinic acetylcholine receptors. Arterioscler Thromb Vasc Biol. 2011;31(4):928-934.

39. Hershey AD. CGRP - The next frontier for migraine. $N$ Engl J Med. 2017;377(22):2190-2191.

40. Giamberardino MA, Costantini R. Challenging chronic migraine: targeting the CGRP receptor. Lancet Neurol. 2017;16(6):410-411.

41. Silberstein SD, Dodick DW, Bigal ME, et al. Fremanezumab for the preventive treatment of chronic migraine. $N$ Engl J Med. 2017; 377(22):2113-2122.

42. Bigal ME, Edvinsson L, Rapoport AM, et al. Safety, tolerability, and efficacy of TEV-48125 for preventive treatment of chronic migraine: a multicentre, randomised, double-blind, placebo-controlled, phase $2 \mathrm{~b}$ study. Lancet Neurol. 2015;14(11):1091-1100.

43. Paul LD. Calcitonin gene-related peptide (CGRP) and migraine. Headache. 2006;46(Suppl 1):S3-S8.

44. Durham PL, Russo AF. Stimulation of the calcitonin gene-related peptide enhancer by mitogen-activated protein kinases and repression by an antimigraine drug in trigeminal ganglia neurons. J Neurosci. 2003;23(3):807-815.

45. Huang D, Ren L, Qiu CS, et al. Characterization of a mouse model of headache. Pain. 2016;157(8):1744-1760.

46. Edelmayer RM, Ossipov MH, Porreca F. An experimental model of headache-related pain. Methods Mol Biol. 2012;851:109-120.

47. Oshinsky ML, Gomonchareonsiri S. Episodic dural stimulation in awake rats: a model for recurrent headache. Headache. 2007;47(7):1026-1036.

48. Melo-Carrillo A, Lopez-Avila A. A chronic animal model of migraine, induced by repeated meningeal nociception, characterized by a behavioral and pharmacological approach. Cephalalgia. 2013;33(13):1096-1105.

49. Yalcin M, Cavun S, Yilmaz MS, Savci V. The involvement of central cholinergic system in the pressor effect of intracerebroventricularly injected U-46619, a thromboxane A2 analog, in conscious normotensive rats. Naunyn Schmiedebergs Arch Pharmacol. 2005;372(1):31-40.

50. Shimizu T, Tanaka K, Hasegawa T, Yokotani K. Brain alpha4beta2 nicotinic acetylcholine receptors are involved in the secretion of noradrenaline and adrenaline from adrenal medulla in rats. Eur J Pharmacol. 2011;654(3):241-248.

51. Ashkenazi A, Sholtzow M, Shaw JW, Burstein R, Young WB. Identifying cutaneous allodynia in chronic migraine using a practical clinical method. Cephalalgia. 2007;27(2):111-117.

52. Bono F, Salvino D, Mazza MR, et al. The influence of ictal cutaneous allodynia on the response to occipital transcutaneous electrical stimulation in chronic migraine and chronic tension-type headache: a randomized, sham-controlled study. Cephalalgia. 2015;35(5):389-398.

53. Boyer N, Dallel R, Artola A, Monconduit L. General trigeminospinal central sensitization and impaired descending pain inhibitory controls contribute to migraine progression. Pain. 2014;155(7):1196-1205.

54. Liang X, Wang S, Qin G, et al. Tyrosine phosphorylation of NR2B contributes to chronic migraines via increased expression of CGRP in rats. Biomed Res Int. 2017;2017:7203458.
55. Liang $\mathrm{X}, \mathrm{Hu} \mathrm{Q}, \mathrm{Li} \mathrm{B}$, et al. Follistatin-like 1 attenuates apoptosis via disco-interacting protein 2 homolog A/Akt pathway after middle cerebral artery occlusion in rats. Stroke. 2014;45(10):3048-3054.

56. Rashid MH, Ueda H. Neuropathy-specific analgesic action of intrathecal nicotinic agonists and its spinal GABA-mediated mechanism. Brain Res. 2002;953(1-2):53-62.

57. Abdin MJ, Morioka N, Morita K, et al. Analgesic action of nicotine on tibial nerve transection (TNT)-induced mechanical allodynia through enhancement of the glycinergic inhibitory system in spinal cord. Life Sci. 2006;80(1):9-16.

58. Egea J, Buendia I, Parada E, Navarro E, León R, Lopez MG. Antiinflammatory role of microglial alpha $7 \mathrm{nAChRs}$ and its role in neuroprotection. Biochem Pharmacol. 2015;97(4):463-472.

59. Duffy AM, Fitzgerald ML, Chan J, et al. Acetylcholine alpha7 nicotinic and dopamine D2 receptors are targeted to many of the same postsynaptic dendrites and astrocytes in the rodent prefrontal cortex. Synapse. 2011;65(12):1350-1367.

60. Alsharari SD, Freitas K, Damaj MI. Functional role of alpha7 nicotinic receptor in chronic neuropathic and inflammatory pain: studies in transgenic mice. Biochem Pharmacol. 2013;86(8):1201-1207.

61. Abbas M, Alzarea S, Papke RL, Rahman S. The alpha7 nicotinic acetylcholine receptor positive allosteric modulator attenuates lipopolysaccharide-induced activation of hippocampal IkappaB and CD11b gene expression in mice. Drug Discov Ther. 2017;11(4):206-211.

62. Yücel M, Kotan D, Gurol Çiftçi G, Çiftçi IH, Cikriklar HI. Serum levels of endocan, claudin-5 and cytokines in migraine. Eur Rev Med Pharmacol Sci. 2016;20(5):930-936.

63. van Hilten JJ, Ferrari M, Van der Meer JWM, Gijsman HJ, Looij BJ Jr. Plasma interleukin-1, tumour necrosis factor and hypothalamicpituitary adrenal axis responses during migraine attacks. Cephalalgia. 1991;11:65-67.

64. Sarchielli P, Alberti A, Baldi A, et al. Proinflammatory cytokines, adhesion molecules, and lymphocyte integrin expression in the internal jugular blood of migraine patients without aura assessed ictally. Headache. 2006;46(2):200-207.

65. Yilmaz IA, Ozge A, Erdal ME, Edgünlü TG, Çakmak SE, Yalin OO. Cytokine polymorphism in patients with migraine: some suggestive clues of migraine and inflammation. Pain Med. 2010;11(4):492-497.

66. Headache Classification Committee of the International Headache Society (IHS). The International Classification of Headache Disorders, 3rd edition (beta version). Cephalalgia. 2013;33(9):629-808.

67. Abbas M, Rahman S. Effects of alpha-7 nicotinic acetylcholine receptor positive allosteric modulator on lipopolysaccharide-induced neuroinflammatory pain in mice. Eur J Pharmacol. 2016;783:85-91.

68. Lu Y, Cao DL, Jiang BC, Yang T, Gao YJ. MicroRNA-146a-5p attenuates neuropathic pain via suppressing TRAF6 signaling in the spinal cord. Brain Behav Immun. 2015;49:119-129.

69. Shen Y, Zhang ZJ, Zhu MD, Jiang BC, Yang T, Gao YJ. Exogenous induction of HO-1 alleviates vincristine-induced neuropathic pain by reducing spinal glial activation in mice. Neurobiol Dis. 2015;79:100-110.

70. Tanabe K, Kozawa O, Iida H. Midazolam suppresses interleukin-1b-induced interleukin-6 release from rat glial cells. $J$ Neuroinflammation. 2011;8:68.

71. Jiang L, Pan CL, Wang CY, et al. Selective suppression of the JNKMMP2/9 signal pathway by tetramethylpyrazine attenuates neuropathic pain in rats. $J$ Neuroinflammation. 2017;14(1):174.

72. Li J, Zhao PP, HaoT, et al. Urotensin II inhibitor eases neuropathic pain by suppressing the JNK/NF- $\kappa \mathrm{B}$ pathway. $J$ Endocrinol. 2017;232(2):165-174.

73. Huang CT, Tsai YJ. Docosahexaenoic acid confers analgesic effects after median nerve injury via inhibition of c-Jun N-terminal kinase activation in microglia. J Nutr Biochem. 2016;29:97-106.

74. Li ZZ, Guo ZZ, Zhang Z, et al. Nicotine-induced upregulation of VCAM-1, MMP-2, and MMP-9 through the a7-nAChR-JNK pathway in RAW264.7 and MOVAS cells. Mol Cell Biochem. 2015;399(1-2):49-58. 
The Journal of Pain Research is an international, peer reviewed, open access, online journal that welcomes laboratory and clinical findings in the fields of pain research and the prevention and management of pain. Original research, reviews, symposium reports, hypothesis formation and commentaries are all considered for publication.
Dovepress

The manuscript management system is completely online and includes a very quick and fair peer-review system, which is all easy to use. Visit http://www.dovepress.com/testimonials.php to read real quotes from published authors. 